\title{
Unregulated Series Resonant Converter for Interlinking DC Nanogrids
}

\author{
Tomas Manez, Kevin; Zhang, Zhe; Ouyang, Ziwei
}

Published in:

Proceedings of the 12th IEEE International Conference on Power Electronics and Drive Systems (PEDS 2017)

Link to article, DOI:

10.1109/PEDS.2017.8289231

Publication date:

2017

Document Version

Peer reviewed version

Link back to DTU Orbit

Citation (APA):

Tomas Manez, K., Zhang, Z., \& Ouyang, Z. (2017). Unregulated Series Resonant Converter for Interlinking DC Nanogrids. In Proceedings of the 12th IEEE International Conference on Power Electronics and Drive Systems (PEDS 2017) (pp. 647-654). IEEE. https://doi.org/10.1109/PEDS.2017.8289231

\section{General rights}

Copyright and moral rights for the publications made accessible in the public portal are retained by the authors and/or other copyright owners and it is a condition of accessing publications that users recognise and abide by the legal requirements associated with these rights.

- Users may download and print one copy of any publication from the public portal for the purpose of private study or research.

- You may not further distribute the material or use it for any profit-making activity or commercial gain

- You may freely distribute the URL identifying the publication in the public portal 


\title{
Unregulated Series Resonant Converter for Interlinking DC Nanogrids
}

\author{
Kevin Tomas-Manez, Zhe Zhang and Ziwei Ouyang \\ Department of Electrical Engineering \\ Technical University of Denmark \\ Email:ktma@elektro.dtu.dk
}

\begin{abstract}
DC nanogrids have become a subject of interest in recent years due to the increase of renewable energy sources with energy storage systems. Hybrid AC/DC systems with different DC buses are an interesting solution to efficiently supply different AC and DC loads. In this paper, a high efficiency bidirectional converter to interlink a $400 \mathrm{~V}$ DC bus with a $48 \mathrm{~V} \mathrm{DC}$ bus is presented. The proposed converter is based on a LLC resonant converter operating as a DC transformer at a fixed frequency and duty cycle without any complex control strategy. A clear and simplified design procedure for high efficiency operation and optimal self-load regulation is presented. To verify the converter operation, a $1 \mathrm{~kW}$ prototype has been implemented, featuring on maximum efficiency of $96.7 \%$ and a self-regulated output voltage with $3 \%$ of maximum offset from the nominal voltage.
\end{abstract}

\section{INTRODUCTION}

To date, AC electrical systems have been dominant in power systems. However, due to the increase of distributed generation systems based on renewable energy sources, there is an increasing interest towards DC nanogrids [1], [2]. DC nanogrids appear as an effective and efficient solution to integrate several types of renewable energy sources, energy storage systems and household DC loads. Currently there are no standard voltage levels defined for DC home systems. However, some studies [1] endorse the utilization of a high voltage (HV) DC bus of $400 \mathrm{~V}$ together with a low voltage (LV) DC bus of $48 \mathrm{~V}$. The $400 \mathrm{~V}$ DC bus complies with the $\mathrm{AC}$ grid line-to-line voltage standards and is compatible with AC appliances. The $48 \mathrm{~V}$ DC bus can interconnect within the residential area photovoltaic (PV) modules, energy storage systems and DC loads such as electronic devices and LED lighting.

As shown in Fig.1, interconnection of both DC buses is performed with interlinking power converters which require certain features, besides high efficiency and power density which are always the present key design features in power converters, for instance, bidirectional operation, to control the power direction going in and out of the nanogrid; isolation between HV and LV DC buses without utilizing low frequency transformers [1]; a system of simple construction and low maintenance [1].

Typical hard-switched isolated converters result in significant switching losses and therefore a limited efficiency. When decreasing the switching frequency switching losses decrease, but dimension of passive components increase. For that reason, an interest towards soft-switching topologies which result in a

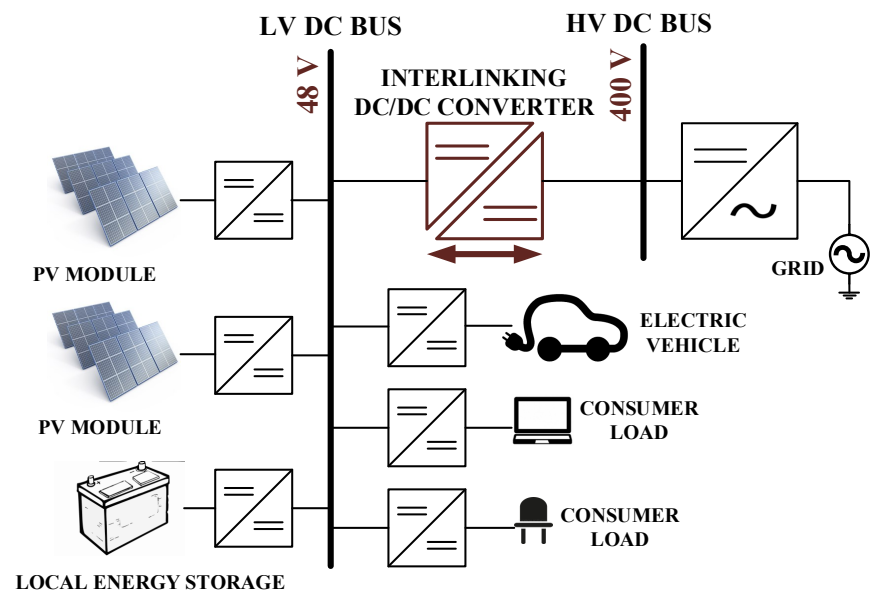

Fig. 1: DC nanogrid in future DC homes

significant reduction of switching losses has increased. Resonant converters represent an interesting solution for improved efficiency due to their inherent soft-switching characteristics.

Among the family of resonant converters, an increased interest towards the LLC resonant converters has arisen during the last years, due to their advantages [3]-[5]: (1) Zero Voltage Switching (ZVS) from light to full load range; (2) low turn-off current for the input side switches; (3) Zero Current Switching (ZCS) for the output side switches. The LLC converter is also an attractive topology for implementing unregulated DC-DC converter modules, due to its inherent load regulation characteristics when operating with a switching frequency close to the resonant frequency [4]. Furthermore, as will be analysed later in this paper, the utilization of an external resonant inductor can be avoided, using solely the leakage inductance of the transformer, which contributes to an improved efficiency and power density. In addition, highest efficiency of LLC converters is obtained when switching at the resonance frequency. Therefore, high efficiency and high power density can be accomplished. Even though the unregulated LLC converter has been addressed in a few publications [6]-[8], a clear and optimal design procedure for bidirectional operation with a distributed resonant tank has not been addressed yet.

In this paper, it is presented a bidirectional unregulated LLC converter, operating as a DC Transformer at $148 \mathrm{kHz}$ 


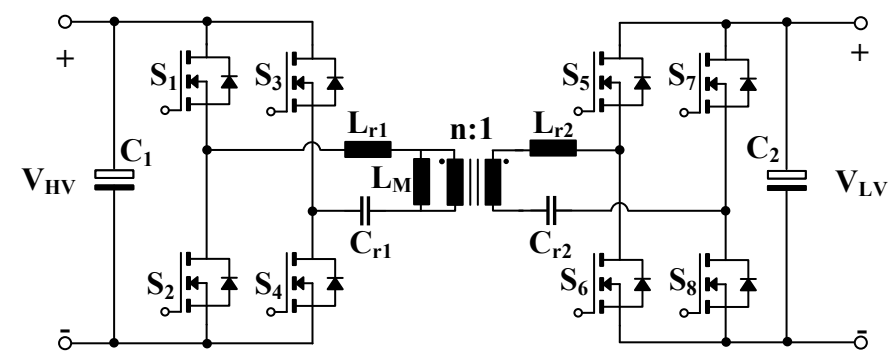

Fig. 2: Topology of the bidirectional LLC converter.

switching frequency and $1 \mathrm{~kW}$ maximum power to link the $400 \mathrm{~V}$ and $48 \mathrm{~V} \mathrm{DC}$ buses for the future smart DC homes. A clear and simplified design procedure for optimal operation is proposed and verified with simulation and experimental results. The design methodology is optimised to reduce the input and output voltage variation from their nominal values and to assure soft-switching conditions for the entire power load with a minimum magnetizing transformer current.

\section{Circuit CONFIGURATION AND OPERATION PRINCIPLE}

The proposed topology is shown in Fig.2. The power converter is based on a LLC converter with H-bridge cells. The high voltage side (HVs) refers to the $400 \mathrm{~V} \mathrm{DC}$ bus and the low voltage side (LVs) refers to the $48 \mathrm{~V}$ DC bus. In hybrid AC/DC grids, generally, the grid-tied inverter regulates the high voltage at the HVs, as explained in [1]. Therefore the voltage on the HVs of the interlinking converter is assumed constant at $400 \mathrm{~V}$ in the design procedure.

As proposed in [10] and [11], because of the bidirectional power flow, the LLC resonant tank is distributed on the primary and secondary side of the transformer. In [10], the LLC converter with a distributed resonant tank is named as CLLC converter. The CLLC converter allows ZVS of primary switches and ZCS of output rectifier for the entire power load regardless the power flow direction. In addition, a symmetrical gain of the resonant tank can be achieved if the primary and secondary side resonant networks are symmetrically designed [11]. In Fig. 2 the transformer is modelled with a turns ratio $n$ : 1 and a magnetizing inductance $L_{m}$ referred to the HVs. The resonant inductors are $L_{r 1}$ on the HVs and $L_{r 2}$ on the LVs. The resonant inductors can by composed by an external inductor in series with the leakage inductance of the transformer or only by the leakage inductance. The resonant capacitors are modelled as $C_{r 1}$ on the $\mathrm{HVs}$ and $C_{r 2}$ on the LVs.

One of the key aspects of the LLC transformer is that when switching at the vicinity of the series resonant frequency, the LLC resonant tank features a high inherent load regulation due to the small output impedance as verified in [4]. In Fig.3 the gain of a LLC resonant tank in terms of normalized frequency for different power levels is shown. The normalized frequency is calculated in (1). As can be seen from Fig.3, when operating at $f_{n}$, the gain of the resonant tank is kept constant to unity from light load to rated power.

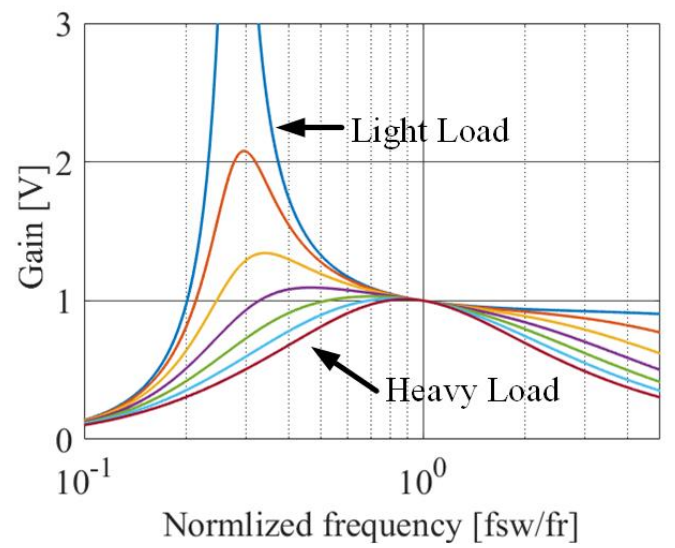

Fig. 3: Typical gain curves of a LLC resonant tank for different loads.

As proposed in [9], the interlinking converter is intended to operate as a dc transformer. Due to the inherent load regulation characteristics of the LLC tank, the converter can operate with a fixed duty cycle of $50 \%$ and a switching frequency for $f_{n}=$ 1. Then, the transformer turns ratio can be selected to obtain the desired voltage gain $n$ as shown in (2). The switches at the input port are actively switched while the output port switches are driven with a continuous low gate signal, and thus using the body diodes as a passive rectifier.

As explained in [8], the LLC converter outperforms when switching at $f_{n}=1$, since ZVS of primary side switches and ZCS of the secondary side rectifiers can be ensured while the circulating current is minimized. However, in practice is not possible to keep the switching frequency at $f_{n}=1$ without using any kind of close loop control, as proposed in [8], due to, for instance, parasitic components, tolerances of passive and active components, ageing and delays in the switching signals. Therefore, the optimal operating point is chosen below the resonance frequency at $0.97<f_{n}<0.99$, which still allows ZVS while keeping a low circulating current and gives some safety margin to avoid operation above the resonance frequency and thus, ensuring ZCS operation.

$$
\begin{gathered}
f_{n}=\frac{f_{s w}}{f_{r}} \quad \omega_{n}=\frac{\omega}{\omega_{r}} \\
n=\frac{V_{H V}}{V_{L V}}
\end{gathered}
$$

\section{A. DC Gain analysis}

When operating with a switching frequency of $f_{n}=1$, the first harmonic approximation (FHA) can be used to derive the transfer function of the CLLC resonant tank. Fig.4 shows the AC equivalent circuit using the FHA when the LVs operates as a load. The output equivalent load, derived in [3], is modelled with $R_{a c}$ and can be calculated in (3).

$$
R_{a c}=\frac{8}{\pi^{2}} \frac{V_{L V}^{2}}{P_{\text {out }}} \quad R_{a c}^{\prime}=n^{2} R_{a c}
$$




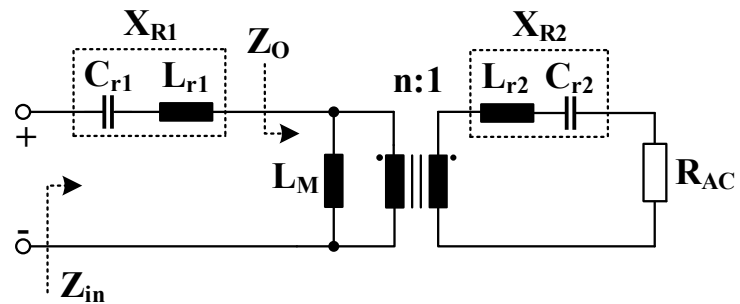

Fig. 4: AC equivalent circuit.

where $P_{\text {out }}$ refers to the the output power and $R_{a c}^{\prime}$ refers to the equivalent ac load referred to the HVs.

The transfer function of the resonant tank can be derived from (4).

$$
H_{C L L C}(j \omega)=\frac{Z_{o}(j \omega)}{Z_{i n}(j \omega)} \frac{R_{a c}^{\prime}}{X_{R 2}^{\prime}(j \omega)+R_{a c}^{\prime}}
$$

where $X_{R 2}^{\prime}(j \omega)$ refers to the reactance of the LVs resonant tank referred to the HVs, $Z_{i n}(j \omega)$ and $Z_{o}(j \omega)$ refer to the input and output impedances of the resonant network.

$Z_{i n}(j \omega)$ and $Z_{o}(j \omega)$ can be calculated with (5) and (6).

$$
\begin{gathered}
Z_{i n}(j \omega)=X_{R 1}(j \omega)+Z_{o}(j \omega) \\
Z_{o}(j \omega)=\left[X_{L_{M}}(j \omega)^{-1}+\left(X_{R 2}^{\prime}(j \omega)+R_{a c}^{\prime}\right)^{-1}\right]^{-1}
\end{gathered}
$$

The reactances are defined as shown in (7), (8) and (9).

$$
\begin{gathered}
X_{L_{M}}(j \omega)=j \omega L_{M} \\
X_{R 1}(j \omega)=j Z_{r 1}\left(\omega_{n}-\frac{1}{\omega_{n}}\right) \\
X_{R 2}^{\prime}(j \omega)=j Z_{r 2}^{\prime}\left(\omega_{n}-\frac{1}{\omega_{n}}\right)
\end{gathered}
$$

where $Z_{r 1}$ refers to the characteristic impedance of the resonant tank at the HVs and $Z_{r 2}^{\prime}$ refers to the characteristic impedance of the resonant tank at the LVs referred to the HVs. $Z_{r 1}$ and $Z_{r 2}^{\prime}$ can be calculated with (10) and (11).

$$
\begin{gathered}
Z_{r 1}=\sqrt{\frac{L_{r 1}}{C_{r 1}}} \\
Z_{r 2}^{\prime}=n^{2} \sqrt{\frac{L_{r 2}}{C_{r 2}}}
\end{gathered}
$$

Combining equations (4) to (9) the transfer function of the CLLC resonant tank is obtained and by finding the modulus the dc gain can be calculated as shown in (12).

$$
\begin{gathered}
\left|H_{C L L C}\right|=\frac{1}{\sqrt{R e^{2}+I m^{2}}} \\
R e=\frac{1}{k_{1}}-\frac{1}{k_{1} \omega_{n}^{2}}+1
\end{gathered}
$$

$$
I m=\frac{Z_{r 1}+Z_{r 2}^{\prime}}{R_{a c}^{\prime}}\left(\omega_{n}-\frac{1}{\omega_{n}}\right)+\frac{Z_{r 2}^{\prime}}{R_{a c}^{\prime}} \frac{\left(\omega_{n}^{4}-1\right)\left(\omega_{n}^{2}-1\right)}{k_{1} w_{n}^{4}}
$$

where $k_{1}$ is the inductance ratio between the magnetizing inductor $L_{m}$ and the HVs resonant inductor $L_{r 1}$ defined as shown in (15).

$$
k_{1}=\frac{L_{m}}{L_{r 1}}
$$

In order to obtain a symmetrical gain of the resonant tank regardless the power flow direction and magnitude, the characteristic impedances $Z_{r 1}$ and $Z_{r 2}$ have to match when referred to the same port, as shown in (16).

$$
Z_{r 1}=Z_{r 2}^{\prime}
$$

Then, an equivalent characteristic impedance seen from the HVs can be defined (17).

$$
Z_{r e q}=Z_{r 1}+Z_{r 2}^{\prime}
$$

Taking (16) and (17) into account, the expression in (12) can be further simplified to (18).

$$
I m=\frac{Z_{r e q}}{R_{a c}^{\prime}}\left(\left(\omega_{n}-\frac{1}{\omega_{n}}\right)+\frac{1}{2 k_{1}} \frac{\left(\omega_{n}^{4}-1\right)\left(\omega_{n}^{2}-1\right)}{w_{n}^{4}}\right)
$$

And the converter dc gain, assuming a duty cycle of $50 \%$ and neglecting the dead time, is presented in (19).

$$
H=\frac{V_{L V}}{V_{H V}}=\frac{1}{n}\left|H_{C L L C}\right|
$$

\section{B. ZVS condition}

ZVS operation of the switches at the input port require enough current during the dead-time $t_{d}$ to charge and discharge the MOSFETs output capacitance $C_{\text {oss }}$. During the dead-time interval, there is no power transfer from the input to the output port and the current flowing through the input port is solely circulating current. The circulating current is set by the magnetizing inductance of the transformer as given in (20).

$$
I_{m}=\frac{V_{L V}}{4 n L_{m} f_{s w}}
$$

When switching at the resonance frequency $f_{n}=$ 1 , the maximum magnetizing inductance to successfully charge/discharge the MOSFETs $C_{\text {oss }}$ can be calculated in (21) as verified in [12].

$$
L_{m, \max }=\frac{t_{d}}{8 C_{\operatorname{coss}} f_{r}}
$$

From (21) it can be observed that for a given $C_{\text {oss }}$ there are multiple combinations of $L_{m}$ and $t_{d}$ which result in successful ZVS operation. Larger $t_{d}$ results in a larger magnetizing inductance and thus, lower circulating current (20). On the other hand, an increase of $t_{d}$ can result in additional drawbacks. An increase of $t_{d}$ reduces the effective duty cycle, meaning that 


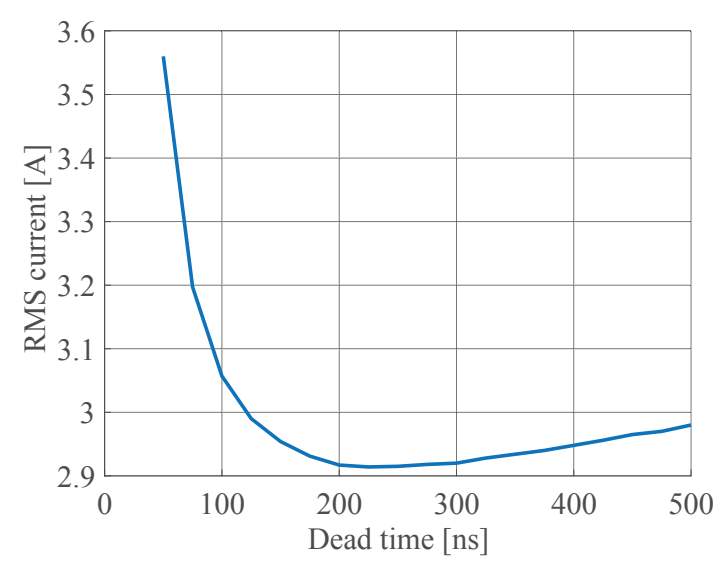

Fig. 5: Current through the HVs of the transformer versus dead time with optimal $L_{m}$ for $C_{o s s}=230 \mathrm{nF}$ at rated output power $P_{\text {out }}=1 \mathrm{~kW}$.

the interval of time for energy transfer is smaller. Therefore, the resonant current has to increase to compensate for the duty cycle loss, which in turn causes an increase of the rms current. In addition, considering the voltage drop across the body diodes of the MOSFETs (approximately $0.9 \mathrm{~V}$ for Silicion devices and larger than $2 \mathrm{~V}$ for Silicon Carbide and Gallium Nitride devices), a longer dead time can result in higher losses during the freewheeling interval.

To quantitatively analyze the effect of the dead time, the optimal $L_{m}$ for different $t_{d}$ and a given $C_{o s s}$ have been calculated from (21). Then, with SPICE simulations the rms current flowing through the primary side of the transformer has been measured. Fig. 5 shows the dead-time versus rms current for different combinations of $L_{m}$ and $t_{d}$. It can be observed that the lowest rms current is comprised between $150 \mathrm{~ns}-300 \mathrm{~ns}$, and above $300 \mathrm{~ns}$ the rms current starts rising again.

\section{Resonant components selection}

Selection of the resonant inductors $L_{r 1}, L_{r 2}$ and capacitors $C_{r 1}$ and $C_{r 2}$, require of special attention as they will also affect the soft-switching conditions and the load regulation characteristics of the converter.

In order to ensure ZVS of the primary side switches, the resonant tank has to operate with an inductive impedance as explained in [5]. Referring to Fig.3, it can be observed that with an increasing output power the resonant tank gain decreases and the gain peak value moves towards the resonant frequency. When the slope of the gain curve becomes positive and the gain drops below unity at the switching frequency, the resonant tank impedance becomes capacitive and hence, ZVS switching operation is hindered. This results in a limitation on the power range due to the operation with fixed switching frequency. The analytical determination of the operation boundaries between capacitive and inductive impedance has already been addressed in many publications. In this paper,

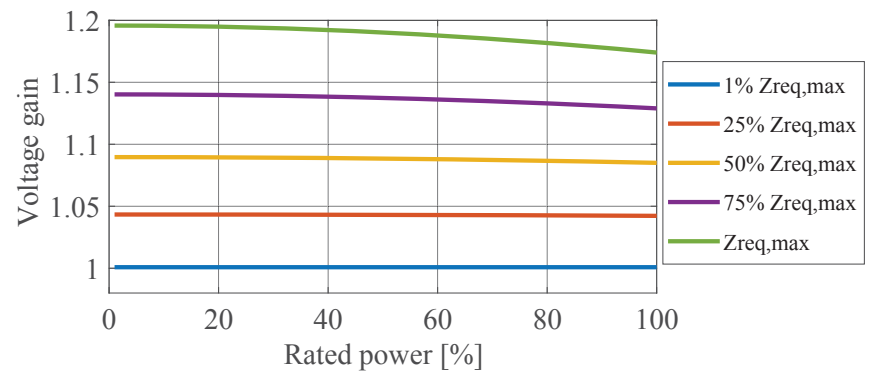

Fig. 6: CLLC resonant tank gain for different $Z_{r e q}$, a fixed $L_{m}$ and $f_{n}=0.97$.

the criterion derived in [5] has been utilized, which limits the output load to the inequality shown in (22).

$$
R_{a c} \geq \sqrt{\frac{L_{m}}{C_{r}}}
$$

In [9], condition (22) has been recombined and generalized for resonant converters with more than one resonant tank as shown in (23).

$$
Z_{r e q} \leq \frac{R_{a c, m i n}^{2}}{\omega_{r} L_{m}}
$$

where $R_{a c, \min }$ is the equivalent load at the converter rated power.

Once the maximum equivalent characteristic impedance of the resonant tank is obtained, the voltage gain of the CLLC resonant tank can be analyzed by analyzed using (12) for different power ratings and the required magnetizing inductance calculated with (21). Fig.6 shows the voltage gain of the resonant tank for different values of $Z_{r e q}$ below the maximum allowed in terms of rated power. As can be observed, the lowest possible characteristic impedance gives the best load regulation characteristics of the resonant tank.

Since the resonance frequency is a fixed design parameter, the characteristic impedance will define the resonant capacitor as shown in (24).

$$
C_{r 1}=\frac{2}{Z_{r e q} \omega r} \quad C_{r 2}=\frac{2 n^{2}}{Z_{r e q} \omega r}
$$

The rms voltage across the capacitor can be calculated with (25).

$$
V_{c r 1, r m s}=\frac{I_{p e a k} Z_{r e q}}{2 \sqrt{2} f_{n}}
$$

$I_{\text {peak }}$ refers to the peak current of the resonant current flowing through the HVs, and can be approximated with (26 according to [12].

$$
I_{\text {peak }}=\sqrt{\frac{4 V_{H V}^{2}}{\pi R_{a c}^{\prime}}+\frac{2 V_{H V}}{\pi^{2} f_{r} L_{m}}}
$$

Fig.7a and $7 \mathrm{~b}$ show the capacitor required and the rms voltage across the capacitor for different $Z_{r e q}$ in per unit, 


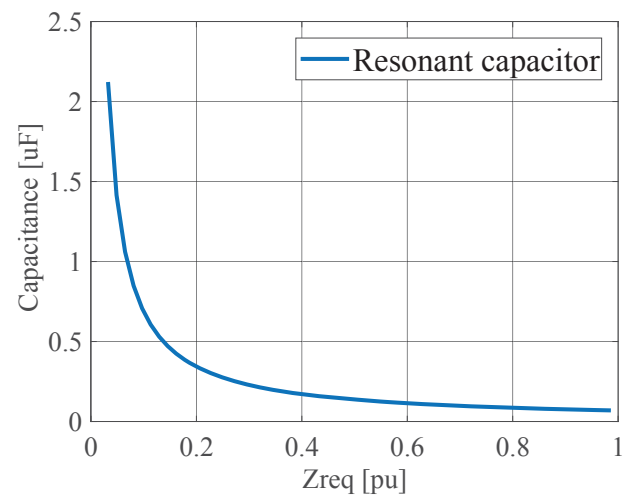

(a)

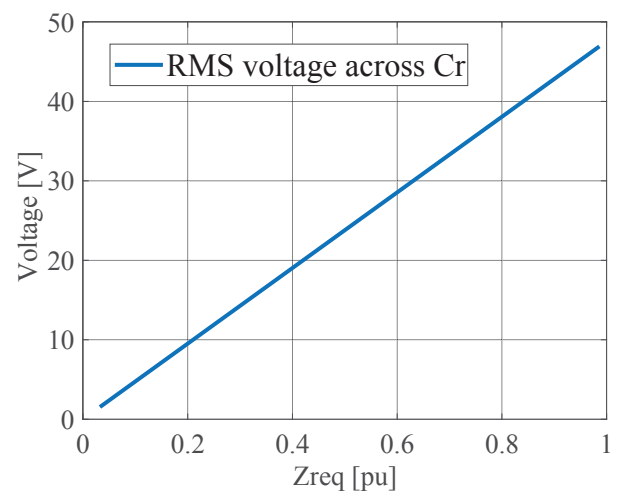

(b)

Fig. 7: Required resonant capacitor at the HVs (a) and RMS voltage (b) in terms of the equivalent characteristic impedance in $\mathrm{pu}$, where $Z_{\text {req }}[\mathrm{pu}]=Z_{\text {req }} / Z_{\text {reqmax }}$.

being the base value the maximum allowed $Z_{\text {req }}$. The lower the characteristic impedance of the resonant tank, higher is the capacitor required but lower the rms voltage across it. Therefore, a low characteristic impedance will also reduce the voltage stress of the resonant capacitors. The minimum characteristic impedance is achieved when using the leakage inductance of the transformer as the resonant inductor. Then, the external resonant inductors can be avoided, reducing in that way the converter losses and increasing power density.

\section{EXPERIMENTAL RESULTS}

A $1 \mathrm{~kW}$ prototype, shown in Fig.8, was realized to verify the operation of the proposed topology. The converter specifications are given in Table I and the design parameters are given in Table II. The switches used on the HVs are IPW65R420CFD $(650 \mathrm{~V}, 0.49 \Omega)$ and on the secondary side IPP034N08N5 (80 V, $3.4 \mathrm{~m} \Omega)$.

A planar E64/10/50 core was used to built the transformer with a gap of $20 \mu \mathrm{m}$ to obtain the required magnetizing inductance $L_{m}$. By measuring the transformer with an impedance analyzer, the leakage inductance was extracted. Then, the theoretical values for the resonant capacitors $C_{r 1}$ and $C_{r 2}$ were calculated for the desired resonance frequency and the minimum characteristic impedance of the resonant tank with

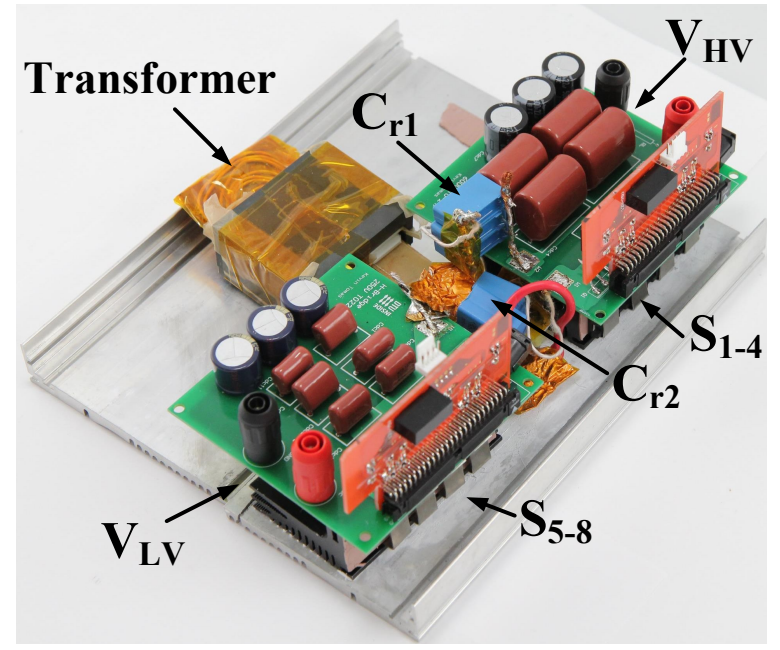

Fig. 8: Picture of the converter prototype.

TABLE I: Specifications

\begin{tabular}{ll}
\hline Parameter & Value \\
\hline$V_{H V}$ & $400 \mathrm{~V}$ \\
$V_{L V}$ & $48 \mathrm{~V}$ \\
$P_{\max }$ & $1 \mathrm{~kW}$ \\
$f_{\text {sw }}$ & $148 \mathrm{kHz}$ \\
\hline
\end{tabular}

TABLE II: Design parameters and components

\begin{tabular}{ll}
\hline Parameter & Value \\
\hline$n$ & 8.3 \\
$t_{\text {dead }}$ & $175 \mathrm{~ns}$ \\
$S_{1-4}$ & IPW65R420CFD \\
$S_{5-8}$ & IPP034N08N5 \\
$L_{m}$ & $440 \mu \mathrm{H}$ \\
$L_{r 1}$ & $5.6 \mu \mathrm{H}$ \\
$L_{r 2}$ & $81 \mathrm{nH}$ \\
$C_{r 1}$ & $13.8 \mu \mathrm{F}$ \\
$C_{r 2}$ & $200 \mathrm{nF}$ \\
\hline
\end{tabular}

(24). However, due to the low inductance at the LVs, the parasitic inductances from the PCB traces and the MOSFET leads slightly reduced the resonance frequency of the LVs. By operating the converter at maximum load and observing the current waveforms, the resonant capacitors were adjusted to obtain a resonance frequency of $150 \mathrm{kHz}$.

\section{A. Steady-state waveforms}

The steady-state experimental waveforms under operation from HVs to LVs are shown in Fig.9 and 10. Fig.9 shows HVs waveforms at $10 \%$ and $100 \%$ rated power. In all cases the switches operate in ZVS, since it does not depend on the load, but on the circulating current. From Fig.9 it can also be observed the effect of the reverse recovery current of the body diode. Even though the MOSFET $S_{2}$ successfully achieves ZVS (and presumably also $S_{3}$ ), the reverse recovery current might still flow through the body diode of $S_{1}$ and $S_{4}$, which might introduce additional conduction losses. Therefore, for an optimal operation, MOSFETs with low reverse recovery energy body diodes should be selected. In Fig.10 the output 


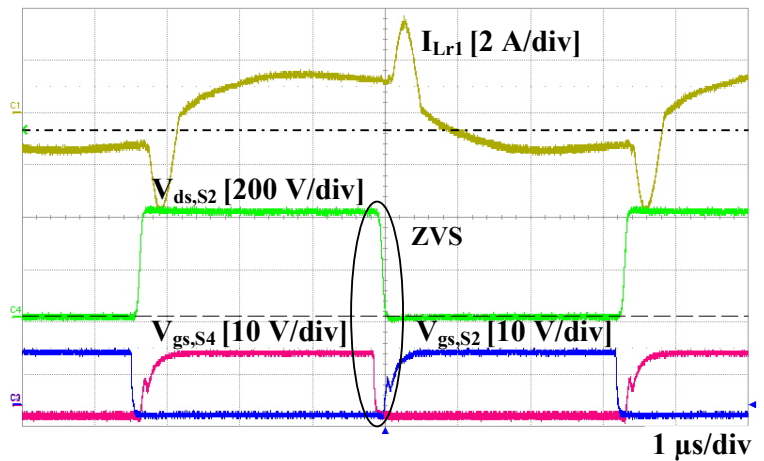

(a) $10 \%$ rated load

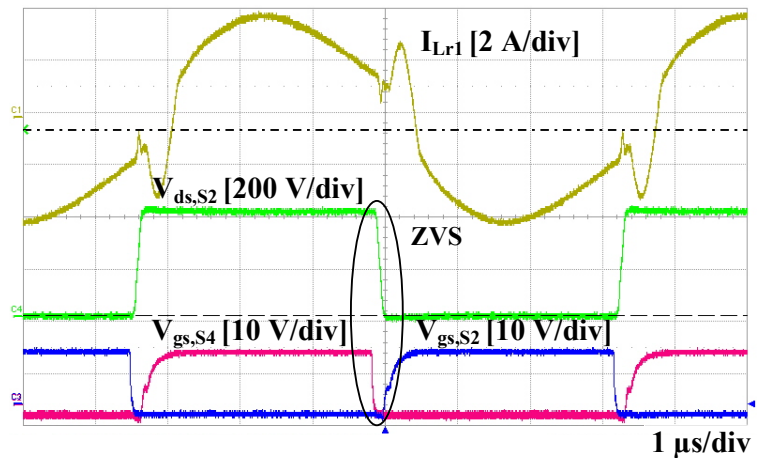

(b) $100 \%$ rated load

Fig. 9: HVs waveforms when power transfer occurs from HVs to LVs.

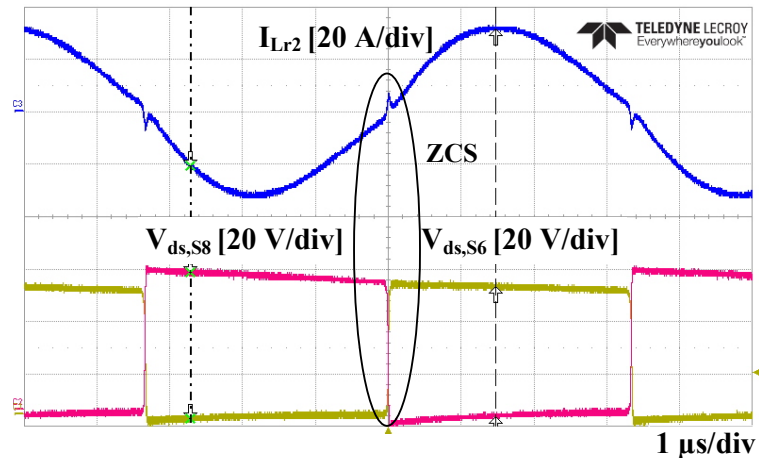

Fig. 10: LVs waveforms when power transfer occurs from HVs to $\mathrm{LVs}$ at $100 \%$ rated load.

waveforms at $100 \%$ rated power are shown. It can be observed that at full load both low side switches on the LVs can achieve ZCS.

In Fig. 11 and 12 the steady state waveforms when operating from LVs to HVs are shown. In Fig.11 the ZVS operation of the LVs switches at $10 \%$ and $100 \%$ rated power is demonstrated. Similarly, in Fig.12 the ZCS on the LVs switches is verified. However, in this operation another phenomenon is observed. On the HVs, during the the dead time interval, the output capacitance of the MOSFETs resonate with the leakage inductance of the transformer, causing severe oscillations on

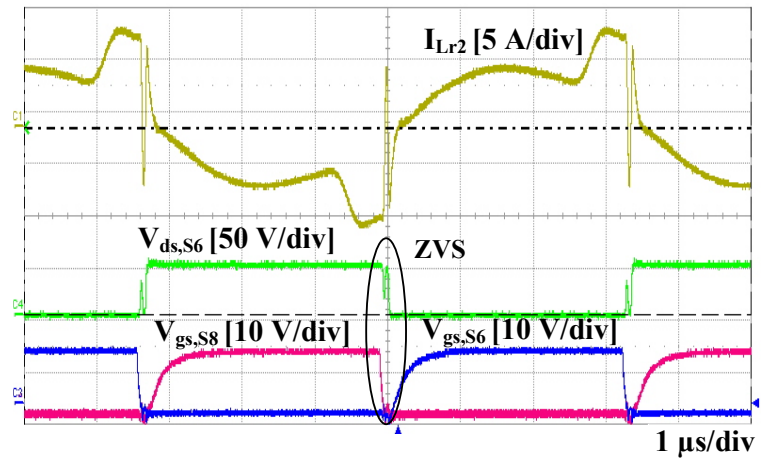

(a) $10 \%$ rated load

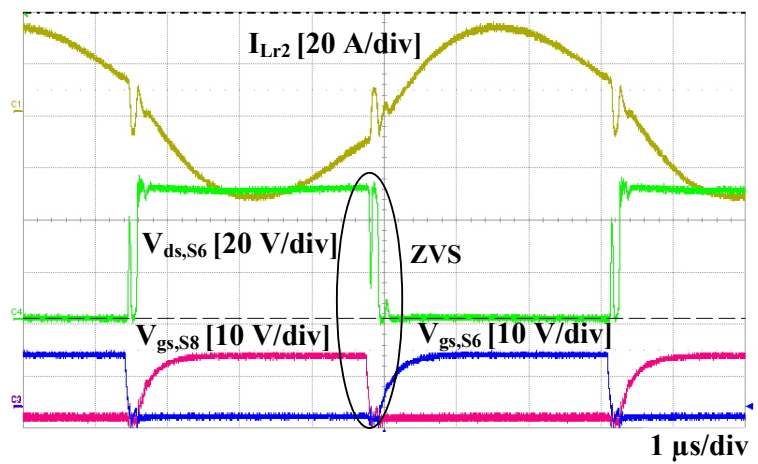

(b) $100 \%$ rated load

Fig. 11: LVs waveforms when power transfer occurs from LVs to HVs.

the current waveform. This is illustrated in Fig.12, when the current waveform approaches to zero and the drain-to-source voltage of $S_{2}$ drops to zero, the resonance begins and high frequency oscillations appear on the current waveform. This oscillations are then reflected to the LVs of the transformer, as can be seen in Fig.11. Since the amplitude of this oscillations is larger than the circulating current on the LVs, the current through the transformer changes direction during the resonance, as can be observed in Fig.11. For that reason, it can be seen in Fig.11 that $V_{d s, S 6}$ starts decreasing after $S_{8}$ is turned-off, but increases again due to the change of the $I_{L r 2}$ current direction. ZVS is still achieved, since when $V_{g s, S 6}$ starts rising, $S_{6}$ is already on. However, this effect might incur in additional losses at the switches.

\section{B. Load regulation}

To evaluate the self-load regulation characteristics of the converter, the prototype was tested under both operating modes by fixing the voltage at the HVs. In the operation mode from HVs to LVs, the converter was supplied by a voltage source of $400 \mathrm{~V}$ and a resistive load on the LVs was used to adjust the power rating. In the operation mode from LVs to HVs an electronic load operating in constant voltage mode at $400 \mathrm{~V}$ was connected to the HVs and a voltage supply in constant current mode was connected to the LVs. Then, the current of the voltage supply was adjusted to control the power rating. 


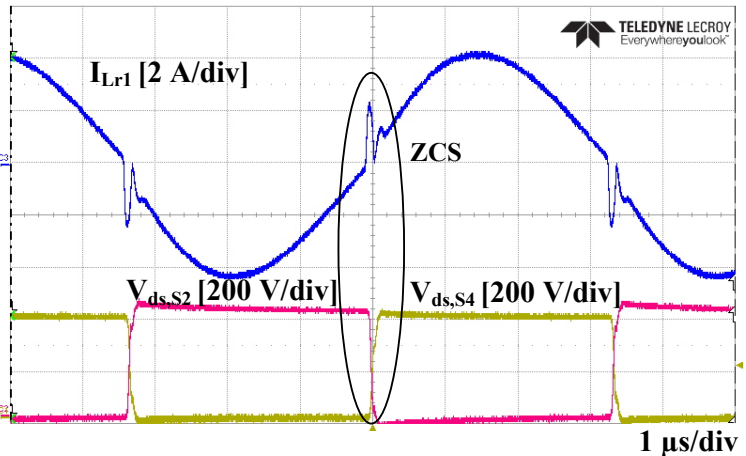

Fig. 12: HVs waveforms when power transfer occurs from LVs to $\mathrm{HVs}$ at $100 \%$ rated load.

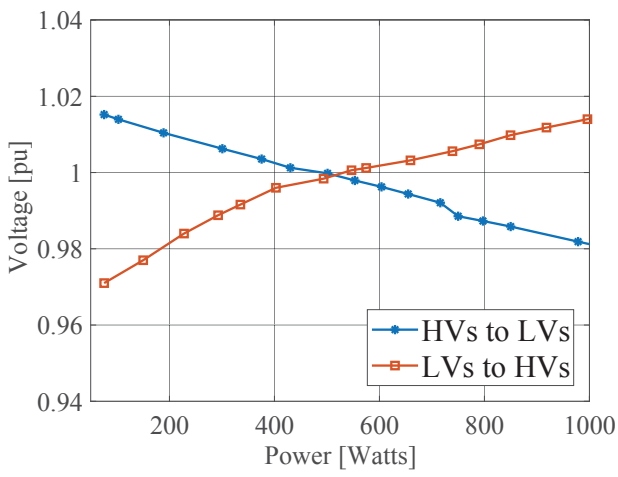

Fig. 13: Voltage regulation results.

The voltage at the LVs was measured and the results are shown in Fig.13. It can be observed that the load regulation characteristics of the converter are outstanding. The highest variation found is $3 \%$ from the nominal value at $75 \mathrm{~W}$.

\section{Efficiency}

Efficiency results are shown in Fig.14. A maximum efficiency of $96.7 \%$ was found when the power flows from LVs to HVs at $700 \mathrm{~W}$. The efficiency at light load was low, which is a common drawback of all resonant converters, due to the large circulating current set by the voltage and the transformer magnetizing inductance, instead of the output power. On the other hand, the efficiency curve remains flat and high for most of the power operating range. The efficiency when the power is transferred from LVs to HVs was almost $2 \%$ higher than when power is transferred from HVs to LVs. This is due to the forward voltage drop of the body diode, since the output bridges operate as a passive rectifier by using the body diodes of the MOSFETs. Even though the switches selected for each bridge have different characteristics, the body diodes forward voltage show a similar behaviour. Therefore, since the LVs handles larger average current than the HVs, the conduction losses became more severe. To highly improve the efficiency, fast recovery diodes with low voltage drop could be mounted in parallel with the LVs switches.

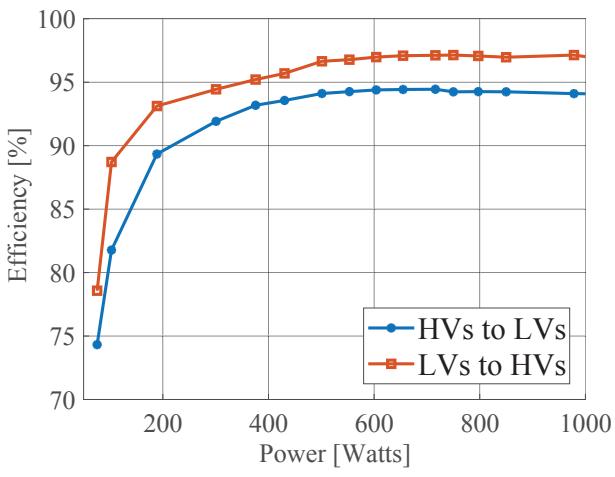

Fig. 14: Efficiency results.

\section{CONCLUSION}

In this paper, a bidirectional series resonant converter with a CLLC resonant network for interlinking DC nanogrids has been presented. The proposed converter operates as an unregulated DC transformer with a fixed switching frequency nearby the resonance frequency and a fixed duty cycle of $50 \%$. The converter has been designed to interlink the $400 \mathrm{~V}$ DC grid with a $48 \mathrm{~V} \mathrm{LV} \mathrm{DC} \mathrm{grid} \mathrm{for} \mathrm{household} \mathrm{applications,} \mathrm{even}$ though it can also be applied to other DC bus voltage levels, such as $12 \mathrm{~V}$ DC bus. The design methodology has been proposed and it has been concluded that for an optimal self-load regulation of the converter, the characteristic impedance of the resonant tank should be minimized. Therefore, to achieve the minimum characteristic impedance, the CLLC resonant network was implemented using the leakage inductance of the transformer together with external capacitors. The resonant tanks at each side of the transformer were selected to match the same resonance frequency. Furthermore, by designing the CLLC tank for the lowest characteristic impedance, the voltage stress across the resonant capacitor was also minimized.

The interlinking converter operation was tested with a $1 \mathrm{~kW}$ prototype. From the experimental results, soft-switching operation from light load to heavy load was verified. However, it was observed that MOSFETs selection is crucial for an optimal operation of the converter. High reverse recovery energy of the MOSFETs' body diode and a high MOSFETs' output capacitance can hinder soft-switching. By measuring the voltage variation at the LVs port while fixing the HVs port voltage, the self-load regulation characteristics of the converter was analyzed. Results showed a maximum voltage variation of $3 \%$ from the nominal value when sweeping the output power until the rated power of the converter. Finally, a maximum efficiency of $96.7 \%$ was reported when power transfer occurs from LVs to HVs.

\section{REFERENCES}

[1] D. Boroyevich, I. Cvetkovic, R. Burgos and D. Dong, Intergrid: A Future Electronic Energy Network?, IEEE, Journal of Emerging and Selected Topics in Power Electronics, Vol. 1, No.3, pp. 127-138, September 2013

[2] P.C. Loh, D. Li, Y.K. Chai and F. Blaabjerg, Autonomous control of interlinking converter with energy storage in hybrid AC-DC microgrid, IEEE, Trans. Industry Applications, Vol. 49, No33, pp. 1374-1382, March 2013 
[3] M.K. Kazimierczuk and D. Czarkowski,Resonant Power Converters, Wiled Ed. Second Edition, 2011.

[4] Z. Pavlovic, J.A. Oliver, P. Alou, O. Garcia and J.A. Cobos, Bidirectional multiple port $d c / d c$ transformer based on a series resonant converter, IEEE, Applied Power Electronics Conference (APEC), pp.1075-1082, May 2013.

[5] I. Lee and G. Moon, The k-Q Analysis for an LLC Series Resonant Converter, IEEE, Trans. Power Electronics, Vol. 61, No. 2, pp. 856-869, January 2014

[6] H. Niu, Y. Pei, X. Yang, L. Wang and Z. Wang, Design of high power density DC Bus Converter based on LLC resonant converter with synchronous rectifier, IEEE, Power Electronics and Motion Control Conference (IPEMC), pp.540-543, May 2009.

[7] R. Ren, S. Liu, J. Wang and F. Zhang, High frequency LLC DCtransformer based on GaN devices and the dead time optimization, IEEE, International Electronics and Application Conference and Exposition (PEAC), pp. 462-467, November 2009.

[8] W. Feng, P. Mattavelli and F.C. Lee, Pulsewidth Locked Loop (PWLL) for Automatic Resonant Frequency Tracking in LLC DCDC Transformer (LLC DCX), IEEE, Trans. Power Electronics, Vol. 28, No.4, pp. 18621869, April 2013.

[9] K. Tomas-Manez, Z. Zhang and Z.Ouyang, Multi-Port Isolated LLC Resonant Converter for Distributed Energy Generation with Energy Storage, IEEE, Energy Conversion Congress and Exposition (ECCE), October 2017.

[10] W. Chen, P. Rong and Z. Lu, Snubberless Bidirectional DCDC Converter With New CLLC Resonant Tank Featuring Minimized Switching Loss, IEEE, Trans. Industrial Electronics, Vol. 57, No.9, pp. 30753086, September 2010.

[11] J. Jung, H. Kim, M. Ryu and J. Baek, Design Methodology of Bidirectional CLLC Resonant Converter for High-Frequency Isolation of DC Distribution Systems, IEEE, Trans. Power Electronics, Vol. 28, No.4, pp. 1741-1755, April 2013.

[12] U. Kundu, K. Yenduri and P. Sensarma, Accurate ZVS Analysis for Magnetic Design and Efficiency Improvement of Full-Bridge LLC Resonant Converter, IEEE, Trans. Power Electronics, Vol. 32, No. 3, pp. 17031706, March 2017. 